\title{
Role of ERCP in acute biliary pancreatitis: yet unanswered
}

We read with great interest the article by Novikov et al. where they reported that endoscopic retrograde cholangiopancreatography (ERCP) decreased in-hospital mortality and length of hospital stay in patients of acute gall stone-induced pancreatitis without cholangitis (AGPNC) [1].

Biliary stones causing transient obstruction at the ampulla is postulated as the triggering event for AGPNC [2]. Thus, it was earlier believed that an urgent ERCP and biliary decompression might ameliorate and modify the disease course. However, previous studies failed to show a benefit for urgent ERCP in terms of mortality and complications in patients without evidence of cholangitis [3]. The current study reported an overall mortality benefit in patients who underwent ERCP compared to those who did not. However, there was no difference in mortality between those who underwent urgent ERCP ( $<24$ hours) vs delayed ERCP ( $>24$ hours). The authors theorize that reduced in-hospital mortality occurred in patients who underwent ERCP between days 3 and 9 and cited initial resuscitation as the reason for the improved mortality. However, the initial treatment for AGPNC is fluid resuscitation and supportive care regardless of whether a patient needs ERCP, unless there is evidence of cholangitis, in which case, antibiotics are needed. ERCP can reduce mortality in patients with persistent cholestasis and cholangitis/sepsis which were excluded in the current study [4]. Thus, the likely reason for benefit of ERCP in the current population is unclear. Although the supplementary table contains codes for details of the ERCP procedures, details about cholangiogram findings and subsequent sphincterotomy and drainage/stenting were not included in the results. Those date probably would have shed some light on the indications and the mechanism of purported benefit of delayed ERCP.
Further, although there was a mortality benefit with ERCP, the duration of hospital stay was prolonged in patients undergoing ERCP, which are two contradictory outcomes and difficult to explain. Also, the number of patients with organ failure and severe pancreatitis at the time of admission was higher in the group that did not have ERCP compared to the intervention group, thus resulting in an apparent mortality benefit in the intervention group. Also, the average length of hospital stay was 5.9 days and the overall mortality was just $1.56 \%$, both of which are very low compared to previously reported large case series, which suggests that a majority had mild disease [5]. Thus, even if there is a benefit, the results cannot be generalized to patients with typical cases of pancreatitis.

In light of these concerns, we believe that the final word is not yet out, and we still need to await the results of large prospective studies to better understand the risks and benefits of ERCP in AGPNC.

\section{Competing interests}

The authors declare that they have no conflict of interest.

The authors

\section{Chhagan Lal Birda, Ashish Agarwal}

Department of Gastroenterology, All India Institute of Medical Sciences, Jodhpur,

Rajasthan, India

\section{Corresponding author}

\author{
Dr. Ashish Agarwal \\ Assistant Professor, Department of \\ Gastroenterology, All India Institute of \\ Medical sciences, Jodhpur, 342001 \\ Rajasthan, India \\ Fax: +11-26588663 \\ drashu123@gmail.com
}

\section{References}

[1] Novikov AA, Fieber JH, Saumoy M et al. ERCP improves mortality in acute biliary pancreatitis without cholangitis. Endosc Int Open 2021; 09: E927-E933

[2] Lerch MM, Saluja AK, Runzi M et al. Pancreatic duct obstruction triggers acute necrotizing pancreatitis in the opossum. Gastroenterology 1993; 104: 853-861

[3] Folsch UR, Nitsche R, Ludtke R et al. Early ERCP and papillotomy compared with conservative treatment for acute biliary pancreatitis. N Engl J Med 1997; 336: 237-242

[4] Fan ST, Lai ECS, Mok FPT et al. Early treatment of acute biliary pancreatitis by endoscopic papillotomy. N Engl J Med 1993; 328: 228-232

[5] Shah AP, Mourad MM, Bramhall SR. Acute pancreatitis: current perspectives on diagnosis and management. J Inflamm Res 2018; 11: 77-85

\section{Bibliography}

Endosc Int Open 2021; 09: E1917

DOI 10.1055/a-1591-0833

ISSN 2364-3722

(C) 2021. The Author(s).

This is an open access article published by Thieme under the terms of the Creative Commons Attribution-NonDerivativeNonCommercial License, permitting copying and reproduction so long as the original work is given appropriate credit. Contents may not be used for commercial purposes, or adapted, remixed, transformed or built upon. (https:// creativecommons.org/licenses/by-nc-nd/4.0/) Georg Thieme Verlag KG, Rüdigerstraße 14, 70469 Stuttgart, Germany

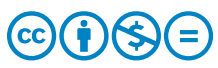

